\title{
PUSAT AKUATIK JAKARTA BARAT
}

\author{
Avine Setiadi ${ }^{1}$, Timmy Setiawan $^{2)}$ \\ 1) Program Studi S1 Arsitektur, Fakultas Teknik, Universitas Tarumanagara, avinesetiadi@gmail.com \\ ${ }^{2)}$ Program Studi S1 Arsitektur, Fakultas Teknik, Universitas Tarumanagara, Timmysetiawan@ft.untar.ac.id
}

\begin{abstract}
Abstrak
Pusat Akuatik ini berlokasi di Jakarta Barat, Kebun jeruk, Jl Panjang. di tengah metropolis proyek ini membuat sebuah wisata, dimana mendukung kepariwisataan serta orang yang membutuhkan wisata ini. Perkembangan minat olahraga minat olahraga akuatik khususnya di jakarta kurang baik dikarenakan malasnya berolahraga. Padahal indonesia merupakan wilayah perairan, atlet renang di indoensia juga masih memiliki potensi. Kolam renang berbasis rekreasi di jakarta barat ini ingin menyediakan fasilitas renang yang diharapakan menyelesaikan masalah tersebut sebagai kawasan yang akan menjadi wisata. Kolam renang berbasis rekreasi merupakan bisnis yang menggirurkan, terbukti dari wahana-wahaan kolam di jakarta yang sudah terkenal. Pada proyek ini akan digabung standar internasional yaitu kolam renang olympic dan kolam wahana (waterpark).
\end{abstract}

Kata kunci: Pusat Akuatik Jakarta Barat

\begin{abstract}
This aquatic center is located in West Jakarta, Kebun Jeruk, in Jl. Panjang. In the middle of this metropolic city, this project caught the eyes of the citizens and enforces tour toward people who need it. Development of interest in aquatic sports, especially in Jakarta, is so low because of the people who are accustomed to being lazy to exercise. Even though Indonesia is a maritime country and there are so much potential aquatic athletes. This recreational-based swimming pool wants to answer the problem as a destination that will become tourist attraction. It's an exciting business. It is evident from the well-known swimming pools in Jakarta. This project will use international standards for its swimming pools and waterpark.
\end{abstract}

Keywords: Aquatik Center West Jakarta

\section{PENDAHULUAN}

Sesuai dengan BPS 2012 (Tabel 1) tentang fungsi olahraga, dibagi menjadi tiga yaitu Olahraga Kesehatan; kebugaran jasmani. Olahraga Prestasi; Olahraga yang membina dan mengembangkan olahraga (atlet) secara terencana, berjenjang dan berkelanjutan melalui kompetisi untuk mencapai prestasi dengan dukungan ilmu pengetahuan dan teknologi keolahragaan.Olahraga Rekreasi; Olahraga yang dilakukan oleh masyarakat dengan kegemaran dan kemampuan yang tumbuh dan berkembang sesuai dengan kondisi dan nilai budaya masyarakat setempat untuk kesehatan, kebugaran dan kegembiraan.

Olahraga dan Rekreasi merupakan salah satu kebutuhan manusia untuk kesehatan jasmani dan rohani yang sangat penting demi mendukung kegiatan kita sehari-hari.Olahraga adalah segala kegiatan yang sistematis untuk mendorong, membina serta mengembangkan potensi jasmani, rohani dan sosial (UU Sistem Keolahragaan Nasional, 2005). Rekreasi adalah aktivitas yang dilakukan pada waktu senggang (lapang) yang bertujuan untuk membentuk, meningkatkan kembali kesegaran fisik, mental, pikiran dan daya rekreasi (baik secara individual maupun secara kelompok) yang hilang akibat aktivitas rutin sehari-hari dengan jalan mencari kesenangan, hiburan dan kesibukan yang berbeda dan dapat memberikan kepuasan dan kegembiraan yang ditujukan bagi kepuasan lahir dan batin manusia. 
Tabel 1.Persentase Penduduk Berumur 10 Tahun ke Atas yang Melakukan Ruang Fungsi Oahraga tahun 2012

\begin{tabular}{|c|c|c|c|c|c|}
\hline \multirow{2}{*}{$\begin{array}{l}\text { Tlpe Daerahy/ } \\
\text { Jenla Kelamin }\end{array}$} & \multicolumn{5}{|c|}{ ThuJuan Olahraga } \\
\hline & $\begin{array}{c}\text { Menjaga } \\
\text { Kesehatan }\end{array}$ & & Rekreagl & Lalnnya & Jumlah \\
\hline [1) & (2) & (3) & (4) & (5) & (5) \\
\hline \multicolumn{6}{|l|}{ Perkotaan $[\mathbb{K}\rangle$} \\
\hline Laki-Iaki & 74,02 & 6,41 & 3,62 & 15,95 & 100,00 \\
\hline Perempuan & 69.59 & 7.75 & 1,76 & 20,90 & 100,00 \\
\hline $\mathbf{L}+\mathbf{P}$ & 72,22 & 6,96 & 2,87 & 17,95 & 100,00 \\
\hline \multicolumn{6}{|l|}{ Perdea-aan (D) } \\
\hline Lakl-lakl & 60,51 & 8,82 & 5,45 & 25,22 & 100,00 \\
\hline Perempuan & 55,50 & 10,93 & 1.53 & 32,04 & 100,00 \\
\hline$L+P$ & 50,47 & 9.67 & 3,86 & 27,99 & 100,00 \\
\hline \multicolumn{6}{|l|}{$\mathbf{K}+\mathbf{D}$} \\
\hline Laki-laki & 60.52 & 7.39 & 4,37 & 19.72 & 100.00 \\
\hline Perempuan & 63,66 & 9,04 & 1,67 & 25.43 & 100,00 \\
\hline$L+P$ & 66,63 & 8,06 & 3,27 & 22,04 & 100,00 \\
\hline
\end{tabular}

Sumber : BPS 2012

Tabel 1. Perkembangan peringkat Indonesia dalam Olimpiade 1988-2012

\begin{tabular}{|c|c|}
\hline Tahun & Peringkat \\
\hline 1988 & 36 \\
\hline 1992 & 19 \\
\hline 1996 & 41 \\
\hline 2000 & 37 \\
\hline 2004 & 48 \\
\hline 2008 & 42 \\
\hline 2012 & 63 \\
\hline
\end{tabular}

Sumber: Wikipedia dan kemenpora

Salah satu cabang olahraga yang ada di dunia adalah renang. Secara umum renang berarti gerakan di air. Dalam suatu kompetisi renang yang dilombakan adalah kecepatan atlet renang dalam berenang. Pemenang dalam perlombaan renang adalah perenang yang tercepat dalam menyelesaikan jarak lintasan yang dilombakan. Gaya yang diperlombakan antara lain gaya bebas, gaya kupu-kupu, gaya punggung, dan gaya dada.

Olahraga renang merupakan olahraga nomor tiga yang paling sering dilakukan setiap minggunya oleh penduduk Indonesia yang berumur di atas 10 tahun, yaitu sebesar $69,7 \%$. Olahraga renang masih lebih jarang dilakukan dibandingkan dengan SKJ dan senam lainnya. 
Tabel 2. Presentasi penduduk berumur 10 tahun ke atas, 2015

\begin{tabular}{|c|c|c|c|c|c|}
\hline \multirow{2}{*}{ Jenis Olahraga } & \multicolumn{5}{|c|}{ Lama Berolahraga (Hari) } \\
\hline & 1 & $2-4$ & $5-6$ & 7 & Jumlah \\
\hline SKJ & 83,3 & 12,2 & 3,9 & 0,6 & 100,0 \\
\hline Senam lainnya & 79,5 & 16.8 & 15 & 2,1 & 100,0 \\
\hline Jogging/gerak jalan & 52,1 & 30.1 & 4,1 & 13.7 & 100.0 \\
\hline Tenis meja & 44.6 & 41,5 & 6.4 & 7.5 & 100.0 \\
\hline Badminton & 42.7 & 50.8 & 3.0 & 4.5 & 100,0 \\
\hline Bola voli & 58.7 & 31,2 & 4,6 & 5,5 & 100,0 \\
\hline Bola basket & 79.6 & 18.6 & 0.9 & 0.9 & 100.0 \\
\hline Sepak bola & 51.7 & 38,0 & 4.4 & 5.9 & 100.0 \\
\hline Renang & 69,7 & 26,7 & 1,6 & 2.0 & 100,0 \\
\hline Bela diri & 40.2 & 52,3 & 2.8 & 4.7 & 100.0 \\
\hline Canur & 32.2 & 53.8 & 4,2 & 9.7 & 100,0 \\
\hline Lainnya & 52,0 & 32,6 & 4.2 & 11.3 & 100.0 \\
\hline
\end{tabular}

Sumber: BPS 2015

\section{KAJIAN LITERATUR}

\section{Architectural Tourism}

Elemen utama pariwisata

- Fasilitas Budaya

- Fasilitas Olah raga

- Fasilitas hiburan

- Karakter fisik

- Fitur budaya dan sosial

Wisata arsitektur tertentu periode waktu atau gaya arsitektur. Oleh karena itu mencakup segala jenis pariwisata yang didedikasikan untuk arsitektur ketika mengacu pada monumen sejarah, aplikasi pariwisata tektural tidak terlalu umum.

- Alam (sungai, pantai, gunung)

- Buatan manusia tetapi awalnya tidak dirancang untuk menarik pengunjung (arkeolog, gereja dll)

- Buatan manusia tujuan untuk pengunjung (Museum, casino, Spa, taman dll)

- Peristiwa spesial (fesitval, area olah raga dll).

\section{Olahraga Rekreasi}

Olahraga rekreasi merupakan kegiatan olahraga waktu luang yang dilakukan secara sukarela oleh perseorangan, kelompok, dan/atau masyarakat seperti olahraga masyarakat, olahraga tradisional, olahraga kesehatan, dan olahraga petualang yang tumbuh dan berkembang dalam masyarakat. Selain itu olahraga rekreasi juga dapat dikatakan olahraga yang dilakukan oleh masyarakat dengan kegemaran dan kemampuan yang tumbuh dan berkembang sesuai dengan kondisi dan nilai budaya masyarakat setempat untuk kesehatan, kebugaran, dan kegembiraan ${ }^{1}$.

Olahraga rekreasi adalah jenis kegiatan olahraga yang dilakukan pada waktu senggang atau waktu-waktu luang (belajar aktif Pendidikan Jasmani dan Kesehatan SMP, Jakarta, Grasindo. 1990). Olahraga rekreasi merupakan olahraga yang dilakukan pada saat waktu luang dengan tujuan untuk mengisi kekosongan waktu. Olahraga rekreasi meliputi aktivitas wahana permainan.

\footnotetext{
${ }^{1}$ Undang-undang No 23 Tahun 2005, Sistem Keolahragaan Nasional).
} 


\section{Olahraga air}

Wahana air berupa:

1. Wave Pool

Kolam renang di mana ada ombak buatan, cukup besar, mirip dengan lautan. Kolam gelombang sering menjadi fitur utama taman air.

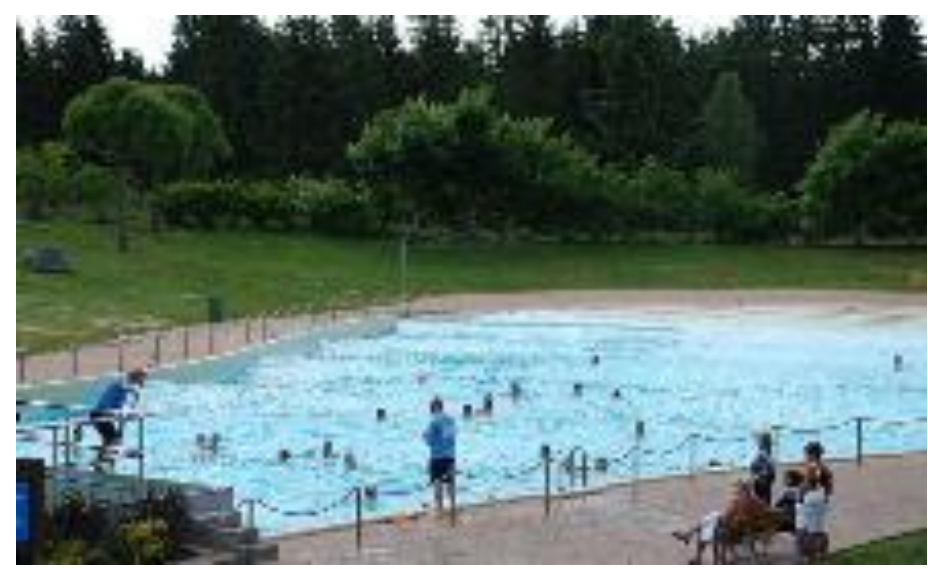

Gambar 1. A wave pool in operation in Swede Sumber: Skara Sommarland vågbad.jpg

\section{Streaming Pool}

Sebagai wahana permainan air bagi pengunjung yang inginmelakukan relaksasi setelah seharian menikmati permainan, dengan menaiki pelampung yang disediakan, pengunjung akan mengitari waterpark sambil bercengkraman dengan teman dan melihat pemandangan sekitar.

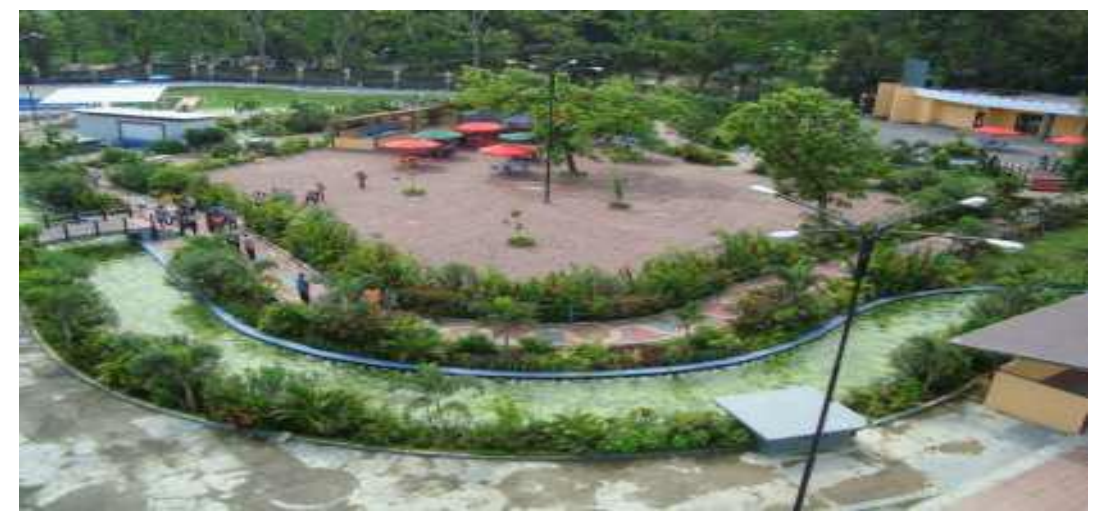

Gambar 2. Kolam Arus

sumber: widuri water park, 4/1/2015

\section{Kolam renang}

Standar kolam renang (perlombaan)

Menurut peraturan FINA (2015-2017) Semua kegiatan lainnya yang diselenggarakan di bawah peraturan FINA harus dilakukan di kolam yang sesuai dengan semua standar minimum berikut ini :

1. Untuk melindungi kesehatan dan keselamatan orang yang menggunakan fasilitas renang untuk tujuan rekreasi, pelatihan dan perlombaan, dadalah tanggung jawab pemilik kolam renang kecuali bila digunakan untuk latihan dan perlombaan harus memenuhi persyaratan yang ditetapkan oleh hukum dan aparat kesehatan di negara mana kolam renang berada.

2. Peralatan untuk perlombaan (misalnya Blok tempat start, tali lintasan, dll) harus sudah 
tersedia..

3. Dinding dinding kolam renang harus sejajar dan tegak lurus dengan jalur lintasan dan permukaan air, dan harus dibangun dari bahan yang padat, permukaan yang tidak licin sampai 0,80 meter dibawah permukaan air, untuk memungkinkan menyentuh dan tidak terpeleset diwaktu bertolak dalam melakukan pembalikan

4. Lintasan (Lanes) harus sedikitnya lebar 2,5 meter, dengan adanya 2 (dua) ruangan yang lebarnya minimal 0,2 meter masing masing di luar lintasan yang terakhir dan pertama.

5. Terdapat minimal 2 petugas yang bertanggung jawab mengawasi wahana

6. Kolam renang untuk race yaitu kolam renang berukuran $50 \mathrm{~m} \times 21 \mathrm{~m}$ dengan kedalaman minimum $2 \mathrm{~m}$ dan maksimum 4,5 m

7. Standar FINA Suhu air kolam renang standar khususnya 25-27 derajat celcius

8. Standar FINA menetapkan untuk kadar ph air kolam antara 7,2 sehingga 7,8 sedangkan kadar klorin antara 1 hingga 2. Jika kadar ph dan klorin kurang dari standar, maka bisa mengakibatkan kerusakan kulit dan mata.

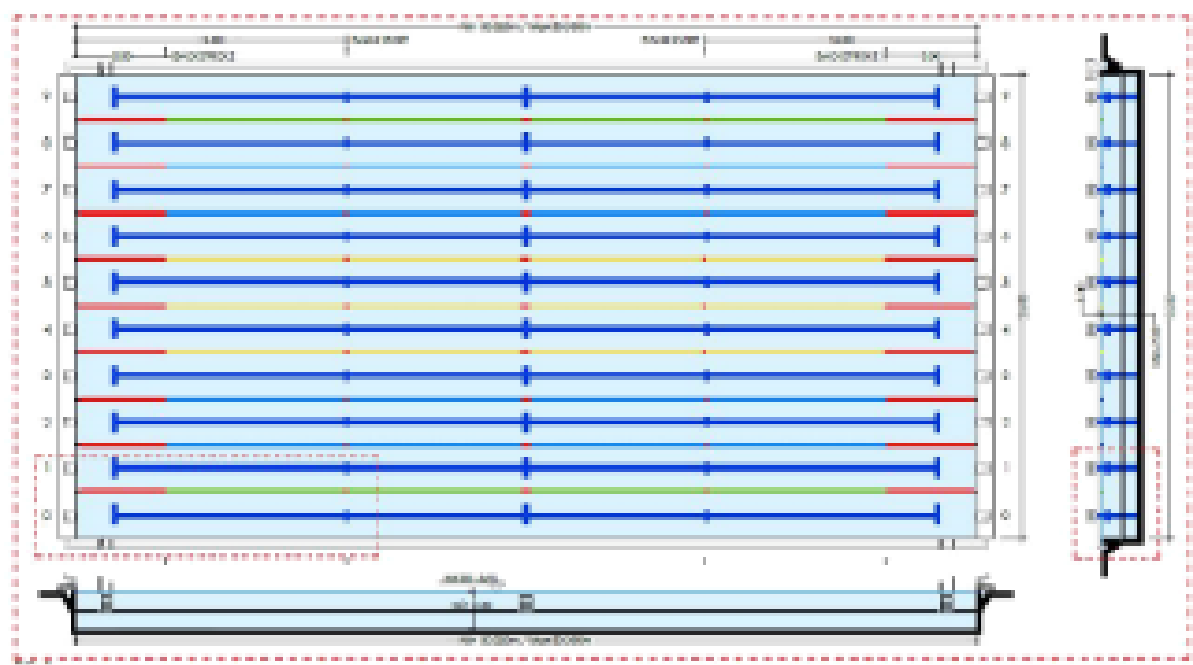

Gambar 3.Kolam Renang Standar Olympic dan Word Championship

Sumber: Fina Facilities Rules 2015-2017

\section{METODE}

Kajian diawali dengan mempelajari pengertian tentang Wisata rekreasi, Olahraga rekreasi, Olahraga air (Water Park) dan standar-standar mengenai Water Park, serta studi banding beberapa Water Park yang telah ada. Dilakukan juga tinjauan mengenai Kota Jakarta. Pendekatan perancangan arsitektural dilakukan dengan pendekatan fungsional, kinerja, teknis, dan konstekstual. Pemilihan tapak dilakukan pada 2 alternatif lokasi dengan menggunakan matriks pembobotan.

\section{DISKUSI DAN HASIL}

Kolam renang yang terdapat di DKI cukup bervariasi.Terdapat kolam renang outdoor maupun indoor. Fungsinya juga dapat digunakan untuk kegiatan rekreasi dan kompetisi renang dan olahraga air namun tidak ada pemisahan antara kegiatan rekreasi dan latihan untuk kompetisi.

Minat terhadap olahraga renang juga dapat dilihat dari adanya klub-klub renang yang ada di DKI. Klub-klub renang yang telah diakui oleh PRSI (Persatuan Renang Seluruh Indonesia) serta nama atlet yang sudah menjuarai sebuah kompetensi. 
Tabel 3. Klub Renang DKI

\begin{tabular}{|c|l|}
\hline & \multicolumn{1}{|c|}{ Klub renang DKI } \\
\hline 1. & Millennium Aquatic 2,087.50 \\
\hline 2. & Pari Sakti Swimming Club 664.50 \\
\hline 3. & Almagary Challenge Swim 389 \\
\hline 4. & Jakarta Aquatics 347. 50 \\
\hline 5. & Bina Taruna 326 \\
\hline 6. & Cucut 307. 50 \\
\hline 7. & Meteor Lintas Aquatik 181 \\
\hline 8. & Pyramid Swimming Club 180.50 \\
\hline 9. & Indonesia Star Aquatic 121 \\
\hline 10. & Tirta Buana Agung 74 \\
\hline 11. & PR Tirta Kencana 78 70 \\
\hline 12. & Jangkar Jakarta Swimming Club 38 \\
\hline
\end{tabular}

Sumber: https://olahraga.kompas.com/read/2017/11/19/11305701/kolam-renang-atlet-dankepentingan-orang-tua

Tabel 4. Jumlah Medali dan Nama Atlet 2007

\begin{tabular}{|c|c|c|c|c|c|c|c|}
\hline Cesang Dahras: & Erents & Nani Asea & Enas & Neres & Perungau & Nans Poireh & Katmas: \\
\hline (1) & 14 & $(3)$ & (⿻) & (5) & 19 & (n) & $(n)$ \\
\hline \multirow[t]{14}{*}{$\operatorname{Reman} 0$} & 1. Wans $100 \mathrm{~m}$ Bachosion & $36 \mathrm{n}$ Vower Buanto & $=$ & 1 & $*$ & 1. Hoted Nortapo & Sprox \\
\hline & & & - & - & - & 2. Niandin & 2Pernon: \\
\hline & 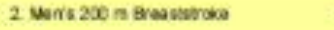 & BlyAfanto & - & 1 & - & 3. Sxon Suano & \\
\hline & & & . & . & . & 4. Tolo Livinto Thamodi & \\
\hline & I Vuris zx n Buserty & Demy nudere Unono & - & 1 & - & 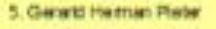 & \\
\hline & 4. Wars 420 mind vosal Vodey & Vhaminal Maber Niantion & - & 1 & $=$ & 3. Marai vasentre & \\
\hline & & & - & $=$ & - & (using) & \\
\hline & 4. Ners Ancooseding & 1 micterd Sen 200 & - & 1 & - & 7 Hag or Heberth & \\
\hline & Fin & 2. Clem Votar Seance & - & . & - & Waing & \\
\hline & & 3 Hery Koniato & . & - & - & & \\
\hline & & Inty Wowo & - & - & - & & \\
\hline & 6. Warrstoe mensonty & Andy Whawo & - & + & 1 & & \\
\hline & 7. Marrs $200 \mathrm{n}$ indivedal Vodoy & Munannad Aver Nisuston & $=$ & + & 1 & & \\
\hline & Towai & & - & 5 & 2 & & \\
\hline \multirow[t]{6}{*}{ Lencat intan } & 1. Whmers tem Plosen & Shemy RanaAnoia & 1 & - & - & 1. AnourRisie Sedan & TEmas \\
\hline & & & - & - & $=$ & 2 Copsituman & 1Prak \\
\hline & 2. Worrens syncheriead 10a Pustom & 1. $8 \mathrm{mom}$ Raha Amwill & - & 1 & - & 3. Yinte fasing & apenros: \\
\hline & & 2 Haflyoni Das Suknatet & . & - & . & & \\
\hline & I Narts $10 \mathrm{~m}$ Pbstern. & Mochomenad Nersilish & - & - & 1 & & \\
\hline & A. Worens syoch an sprigboard & 1. Narr Sipar & - & - & 1 & & \\
\hline
\end{tabular}

Sumber : Kementerian Negara Pemuda dan Olahraga

Untuk mengembangkan potensi yang ada, maka diperlukan pembinaan yang berkesinambungan dan keikutsertaan dalam pertandingan. Dalam pembinaan olahraga renang diperlukan sarana berupa kolam renang yang sesuai dengan standar internasional agar atlet terbiasa berkompetisi dengan kondisi tersebut.

Wisata olahraga air membutuhkan sebuah wahana lain selain kolam renang standar internasional untuk meningkatkan daya tarik masyarakat. Wahana tersebut menjadi tempat liburan favorit keluarga. Adanya beragam wahana air yang tak mungkin temukan di kolam renang biasa membuat daya tarik wisata.

Lokasi yang dipilih adalah lahan kosong milik Negara yang berada pada Jl.Panjang ,Kebun Jeruk. Lahan ini saat ini terlihat masih berupa lahan hijau yang ditumbuhi beberapa pohon, ditutupi tembok. pada beberapa bagian, lahan ini digunakan oleh warga sekitar untuk mendirikan bangunan liar. 


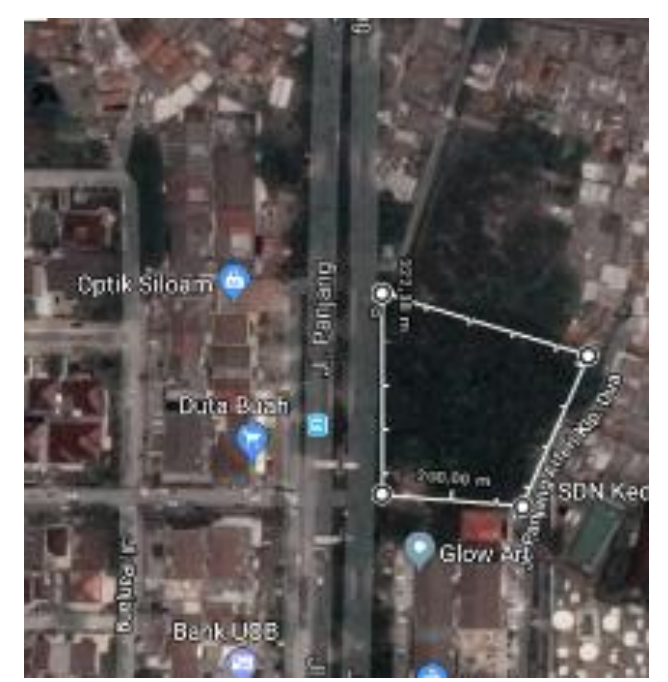

Gambar 4. Lokasi Tapak-1

Sumber: Google map -syuting penulis 2018

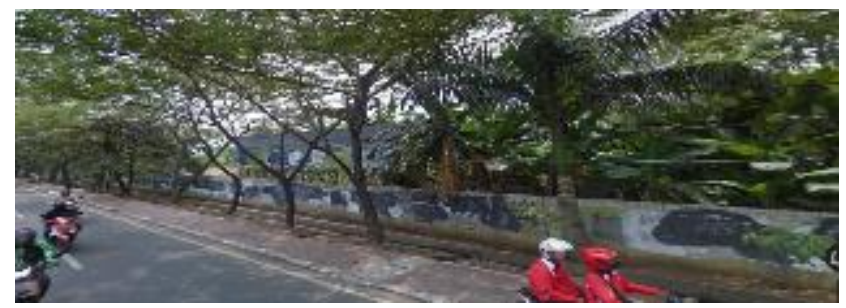

Gambar 5. Lokasi Tapak

Sumber: Analisa Penulis, 2018

Batas Lahan:

- Utara ; Tambal Ban JI Panjang

- Timur ; Sekolah SDN Kedoya Utara JI Panjang Arteri klp Dua Raya

- Selatan ; Glow Art Jl Panjang

- Barat ; Bank Central Asia JI Panjang

Beberapa potensi yang dimiliki oleh lahan ini antara lain adalah;

- Dekat dengan beberapa penginapan umum yang berada pada JI Panjang

- Posisi tapak yang berada di jalan raya memudahkan akses dari segala penjuru kota.

Selain potensi, lahan ini juga memiliki beberapa kekurangan yang harus diperhatikan agar nantinya bangunan yang akan dibuat, yaitu posisi lahan yang dekat dengan jalan utama berada pada arah Barat, hal ini tentunya akan sangat merugikan jika bangunan dibuat mengarah atau berorientasi menuju jalan utama.

Untuk itu harus diperhatikan penentuan posisi entrance bangunan agar tidak menyulitkan dalam perlindungan terhadap sinar matahari. 


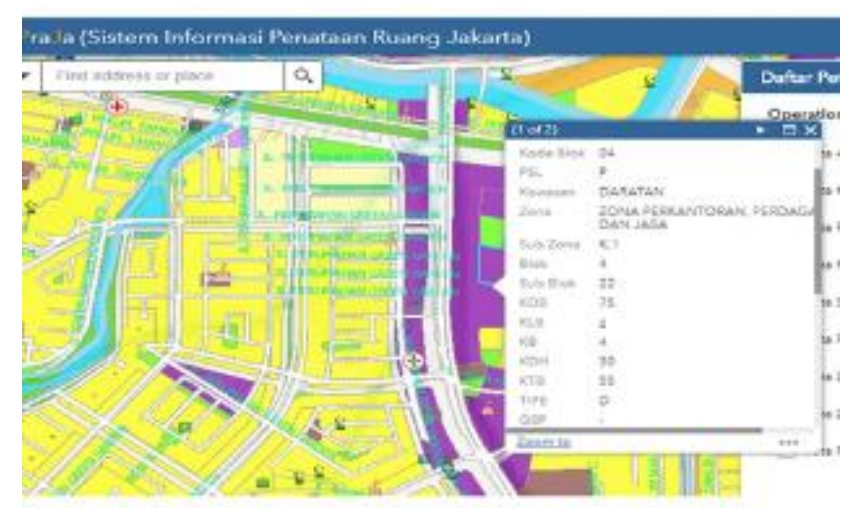

Gambar 6. Sispraja Informasi Tata Ruang Tapak

Perhitungan luas bangunan PROYEK :

Jumlah Luas Total Keseluruhan Bangunan $=20.000 \mathrm{~m} 2$

Aquatik $=14000 \mathrm{~m} 2$

Waterpark $=6000 \mathrm{~m} 2$

Jumlah Luas tapak perencanaan $=30.000 \mathrm{~m} 2$.

\begin{tabular}{|l|l|}
\hline $\begin{array}{l}\text { KLB sesuai } \\
\text { peraturan }=4\end{array}$ & $\begin{array}{l}\text { KLB yang } \\
\text { direncanakan }=4\end{array}$ \\
\hline
\end{tabular}
\begin{tabular}{|l|l|} 
Jumlah luas lantai dasar perencanaan $=7140 \mathrm{M} 2$ \\
\hline $\begin{array}{l}\text { KDB sesuai peraturan } \\
=75 \%=22500 \mathrm{M} 2\end{array}$ & KDB yang direncanakan $=20.000 \mathrm{~m} 2$ \\
\hline
\end{tabular}

Jumlah lantai bangunan perencanaan $=4$

Jumlah lantai bangunan sesuai peraturan $=4(\mathrm{KLB})$

KTB sesuai peraturan

$=55 \%=16500$

KTB yang direncanakan $=12.000 \mathrm{~m} 2$

Jumlah Lantai dibawah tanah (basement) $=4$ (peraturan)

Lantai basement 1

ruang 4500M2

$\mathrm{KDH}$ sesuai peraturan

$=30 \%=9000 \mathrm{~m} 2 \quad \mathrm{KDH}$ yang direncanakan $=9500 \mathrm{~m} 2$

Zona K1 merupakan zona perdagangan namun dapat juga Olahraga

Berikut adalah beberapa kondisi terakhir di lapangan ( Existing ) yang diambil pada 2018 ini adalah: 

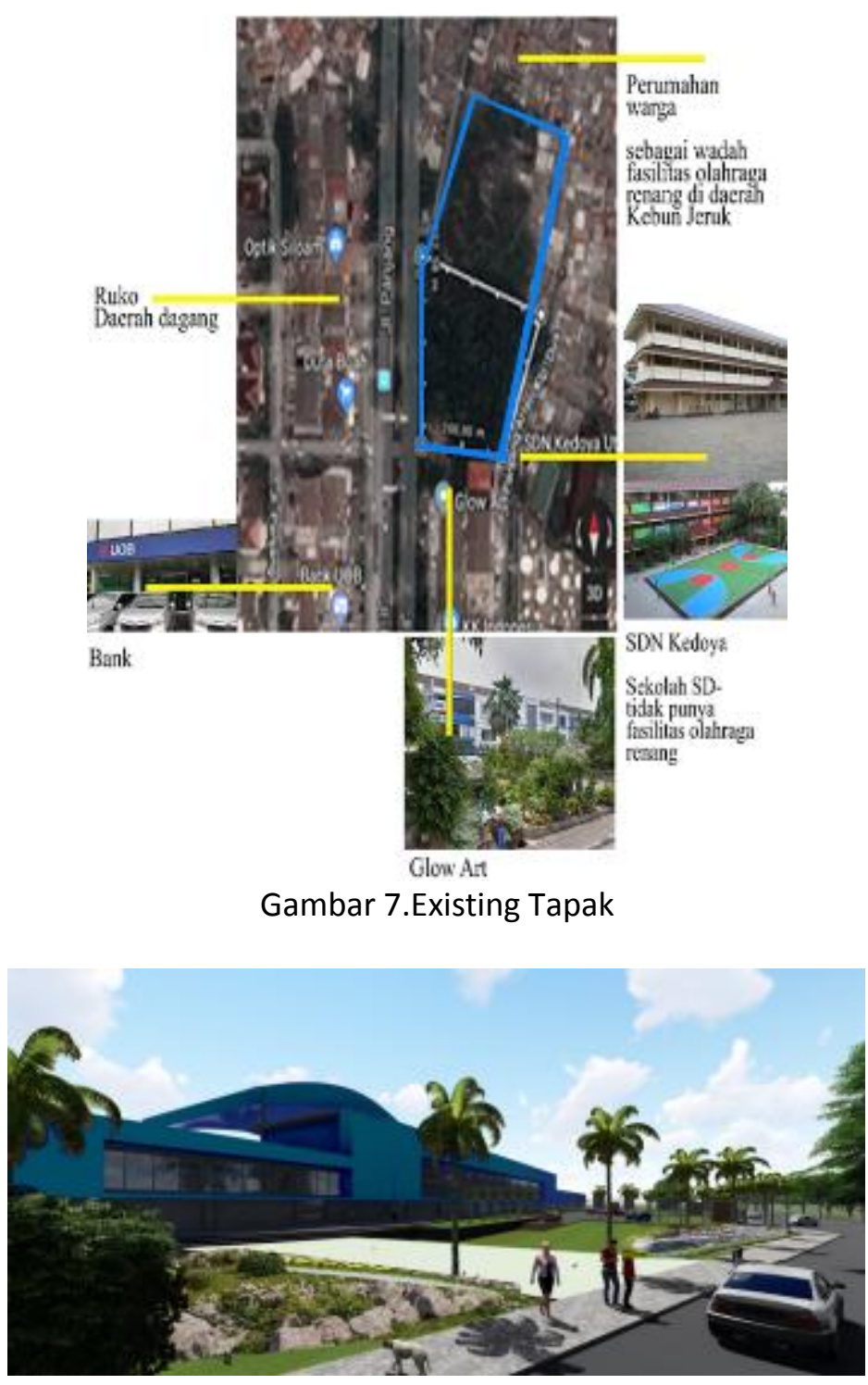

Gambar 8. West Jakarta Aquatik Center

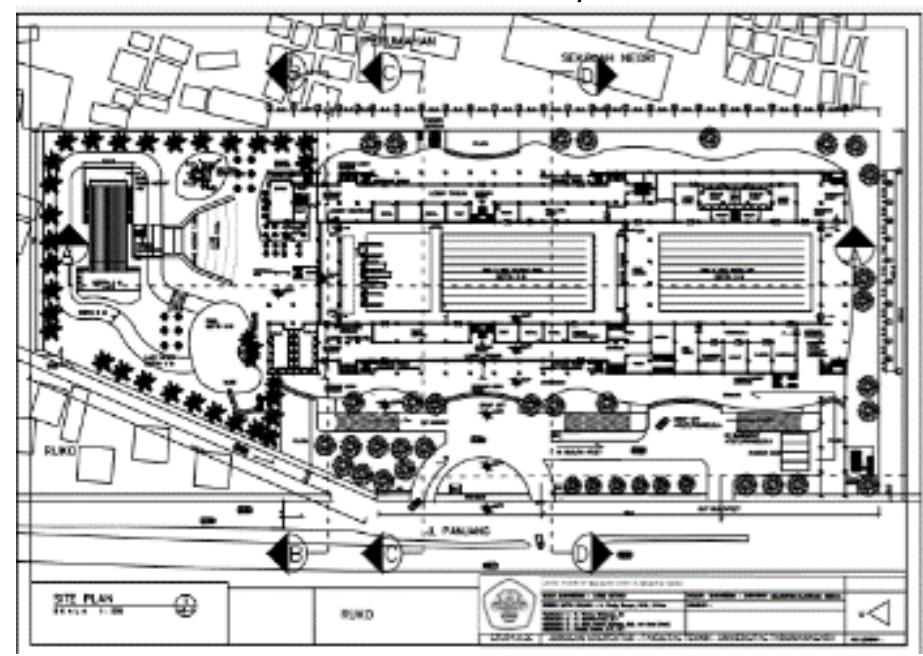

Gambar 9. West Jakarta Aquatik Center Site Plan 


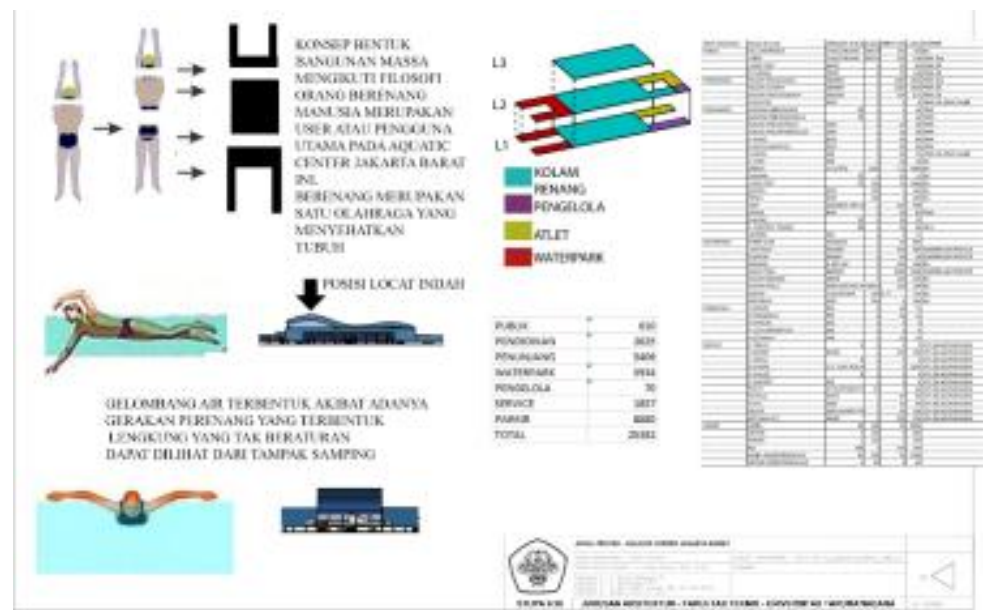

Gambar 10. West Jakarta Aquatik Center Tema dan Program Ruang

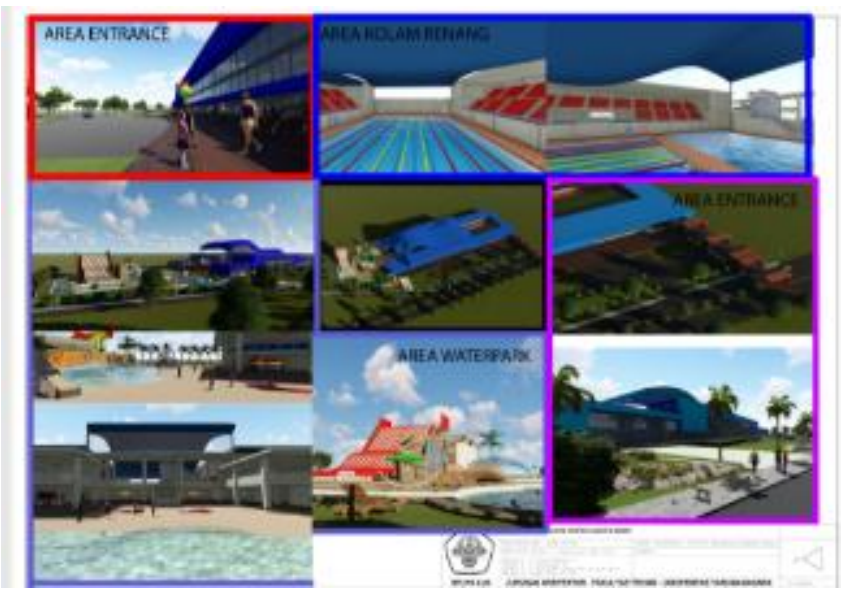

Gambar 11.West Jakarta Aquatik Center Interior dan Eksterior

\section{KESIMPULAN DAN SARAN}

Pusat Akuatik di Kebun Jeruk, Jakarta Barat menjawab isu perkembangan minat olahraga akuatik. Kolam renang berbasis rekreasi di jakarta barat ini ingin menyediakan fasilitas renang yang diharapakan menyelesaikan masalah tersebut sebagai kawasan yang akan menjadi wisata. Pada proyek ini akan digabung standar internasional yaitu kolam renang olympic dan kolam wahana (waterpark).

\section{REFERENSI}

Rudy Surya, Buku architectural tourism, 2018/2019

http:/amp.guardian.com.//artddesign/2017/oct/01/bilbao-effect-frank// diunduh 7 Juli 2018 Http:/Wikipedia dan kemenpora diunduh 7 Juli 2018

https://asiangames2018.id/about/history diunduh 7 Juli 2018

Http:/Kementerian Negara Pemuda dan Olahraga diunduh 7 Juli 2018

Http://BPS 2015.com diunduh 7 Juli 2018

http://data.jakarta.go.id 2017 diunduh 7 Juli 2018

http://Peta Zonasi jak barat 2014 diunduh 7 Juli 2018

http:/ Kemenpora Standar prasarana Olahraga 2016 diunduh 7 Juli 2018

http:/Fina Facilities Rules 2015-2017 diunduh 7 Juli 2018 